\title{
Editorial: Hope for humanity in the Middle East
}

Communicable ophthalmia-the combination of trachoma and acute ophthalmia-remains today the most important cause of preventable blindness, some two million having succumbed out of five hundred million affected. In this WHO Blindness Year it is pertinent for the British fournal of Ophthalmology to publish a working paper which discusses the chronic trachomatous pathway to loss of sight and inseparably related pathway to blindness through acute ophthalmia. The problem is so defined in the first paper of this issue that lay-folk and administrators can readily understand the needless trail of devastation involved, grasp the importance of eradication of hyperendemic trachoma, and be encouraged to take part in the proposed programme of prevention and treatment.

The control of this age-long scourge calls for action by humanists and governments of all creeds and colours, it demands deeds not words, generosity not piety. In a world where medical science knows no boundaries, mankind is afforded once again an opportunity to demonstrate a unity of purpose and to forget, however briefly, its many differences. 